\title{
Inventory Reduction in a Metal-Mechanical Industry Using Logistical Tools
}

\author{
Alejandro H. Martínez-Márquez, Diana Sánchez-Partida, José Luis Martínez-Flores \\ Universidad Popular Autónoma del Estado de Puebla, \\ Puebla, México \\ alejandroheriberto.martinez@upaep.edu.mx, diana.sanchez@upaep.mx, \\ joseluis.martinez01@upaep.mx
}

\begin{abstract}
This paper seeks the critical factors for a correct choice in the components set up along the supply chain. ABC classification was made for all the suppliers according to the supplied items for the company. After a demand analysis, the seasonal nature and trend during the timeline, we used the last four years registers where is shown a decreasing behavior in $30 \%$ of the items; Economic Order Quantity (EOQ), for deterministic $(<20 \%)$ which 58 items represents $64 \%$ of the A classified items into the pull system; and a continuous review model q, R for stochastic (>20\%) which 33 items represents $67 \%, 429$ items $(92 \%)$ are classified as B and 2,128 items $(99 \%)$ are C. We reduced the lot quantity orders in $32 \%$, the re-order points were adjusted according to the EOQ and $\mathrm{q}, \mathrm{R}$ models; Safety stock levels were reduced 55\% representing $\$ 450,000$ pesos against the initial inventory of 1’000,000 pesos.
\end{abstract}

\section{Introduction}

Nowadays more companies acknowledge the importance of stock as a key component for business, even though its role was previously underestimated. Nowadays, stocks are recognized as a main component within the supply chain and other commercial procedures. According to Aznar (1986), the role of stocks in business is increasingly gaining in importance:

For an industrial company, between $25 \%$ and $30 \%$ of the total assets is represented by the row of inventories. Yet, for commercial the financial statements can reach up to $80 \%$ or even a higher percentage. Commonly, part of the resources invested in inventories comes from loans to other companies (Aznar, 1986) representing a high cost impact.

Inventories concentrate the totality of assets that companies require to satisfy the demand of products or services that are offered. The main reasons to justify the maintenance of inventories is to reach economies of scale, to face uncertainty and speculation, to leave out temporal Investment, to smooth the variability of demand, the restrictions of business logistics and the cost of control systems (Nahmias, 2007).

According to Heizer and Render (2001) the costs associated to the inventories can be classified in two categories: ordering costs and maintenance costs. The ordering costs include the specifications, purchase order, suppliers follow-up, office documents 
and administrative staff which are needed to process the orders. The maintenance cost include; the warehouse rental (if it is the case) depreciation, operational costs, taxes, cost of capital opportunity, insurances, financing costs, financial losses, waste, obsolescence, etc. Through this method, the acquisition of materials has to be done using the Just in Time (JIT). However it is not pure JIT since it combines tools from other systems, it is a hybrid version of JIT that fill the gaps that cannot be completed due to an array of deficiencies in the supply chain.

This project is aimed at the personalized products and high volume business unit. It focuses on analyzing -from a single business unit- the 24 thousand part numbers from the stock of direct components for assembly. The objective is to improve the efficiency of purchase processes, to generate savings for the company and to optimize the inventory levels. In a first instance, the basic components of the business unit in question were downloaded. A Pareto of suppliers was applied in order to identify the main part numbers of the company, where the amount of items designated is displayed. Using this information, the supplier that provides more part numbers was selected and the part numbers were classified according to their profit and use. This classification of the articles was used to analyze the behavior of the demand.

In a later stage, the Coefficient of Variability was calculated by using the information gathered from the part numbers selected in order to foretell the behavior of the demand. The results obtained from this process were used to establish the model to be applied the two cases found. Finally, the safety stock was calculated after the results of lot sizes were concluded.

\section{Literary Review}

The Pareto principle -also known as the 80-20 rule or the principle of factor sparsity-, named after the Italian economist, sociologist and engineer Vilfredo Pareto who introduced the concept for the first time, is considered one of the major contributions to microeconomics and a baseline for $\mathrm{ABC}$ analysis. This concept divides the inventory available in three categories based on the income annual volume.

The Pareto principle indicates to separate 'the vital few from the trivial many'. The aim is to apply policies for inventories so that there is a focus on the vital few parts of an inventory instead of the trivial many. It is not realistic to monitor cheap articles with the same emphasis than the costly ones (Heizer J. \& Render B., 2009).

Classifying part numbers in an inventory is of great importance to maintain efficient levels. Dhoka et al (2013) show that in the Analysis ABC -based in the Pareto principle$20 \%$ of articles contribute to $80 \%$ of sales. Generally, this $20 \%$ is composed by articles classified as A and produce the $80 \%$ of the income of the company. In their study they analyze 330 articles from the automotive industry within a specific time frame in order to show the changing behavior of $\mathrm{A}, \mathrm{B}$ and $\mathrm{C}$ categories.

Another tool used is the Economic Order Quantity model or EOQ which allows to determine the amount of items that should be ordered to minimize costs. This model is one of the preferred to achieve a range of demand. It allows to balance the fixed costs per lot and the logistical costs (Roach Bill, 2005). The EOQ is not a complex model, it is based on finding the point where the costs of ordering a product are equal to the costs of maintaining it. 


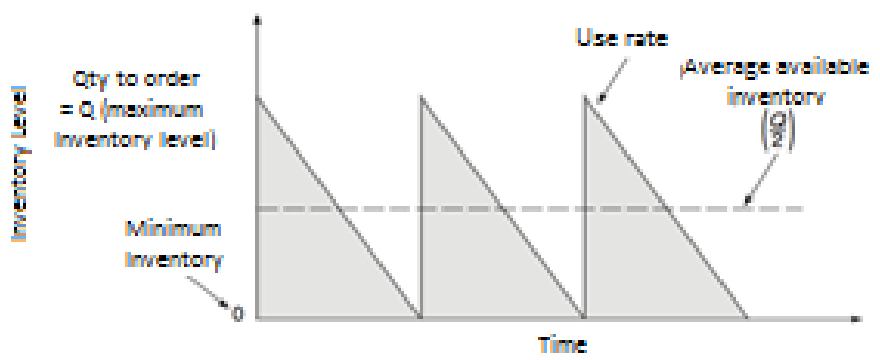

Fig 1. Graphic representation of EOQ model (Heizer, 2009).

The graphic for the inventory use through the time has a dented saw shape, as is illustrated in Fig 1. In the figure Q represents the quantity to be ordered. Generally, when an order is received the inventory level increases from " 0 " to Q units. Due to the constant demand through the time, the inventory decreases in a constant rate during a specific period of time. Every time the inventory level reaches to zero, a new order is placed and received; and once again the inventory level reaches to Q units (represented by vertical lines. The process continue through the time indefinitely (Heizer, J. 2009).

Sipper, D. \& Bulfin, R.L. (1998) determine the q, R model as special for the continuous review system. This model has a unique optimization of service and focus, equivalent to the stochastic version for a deterministic EOQ. Both variables establish the models policy, where $\mathrm{Q}$ represents the order size and $\mathrm{R}$ is the reorder point. The principal issue in the analyzed company, according to the study, is the low rotation and high inventory level. Qing Li et al (2008) describes the problem of no defined demand/production, through the model definition to calculate the lot size, having all the used variables.

Pratap, M., \& Singh, H. (2008), proposed an stochastic inventory model in order to select the economic order to improve the inventory level control, and delete the stock out raw material situation. The result of this study revealed that the companies can save a considerable yearly amount of money adopting the proposed model.

As Mattsson (2007) describes in his study subject, with the showed simulations in his work is a simply way to describe the positive effect of the continuous inventory reviews expressed using equations trying to clarify the model. Below the Figure 2 are showed 2 examples of how the re-order points can be reached, where it is considered a minimal inventory level meanwhile the placed order is triggered to be received during a specific period of time.

The main issue that can be represented in this model, is the stock out for raw material, and is considered in its critical point when the replenishment has not been received, in other words, meanwhile the material is under production with the supplier or in-transit to the needed facilities. For these reasons the lead time plays an important role inside the company's supply chain, creating several ideas to encourage a deep and strong partnership between supplier-client as a single commercial society.

Hopp, Spearman \& Zhang, in its publication Easily Implementable Inventory Control Policies (1997), when customer service depends mainly in the material availability, the problem has a solving estimation with the minimization for the total inventory investment subject to average fill rate restrictions and orders frequency. In 
which the authors selected the $\mathrm{q}, \mathrm{R}$ model as the most appropriated playing the individual inventory role.
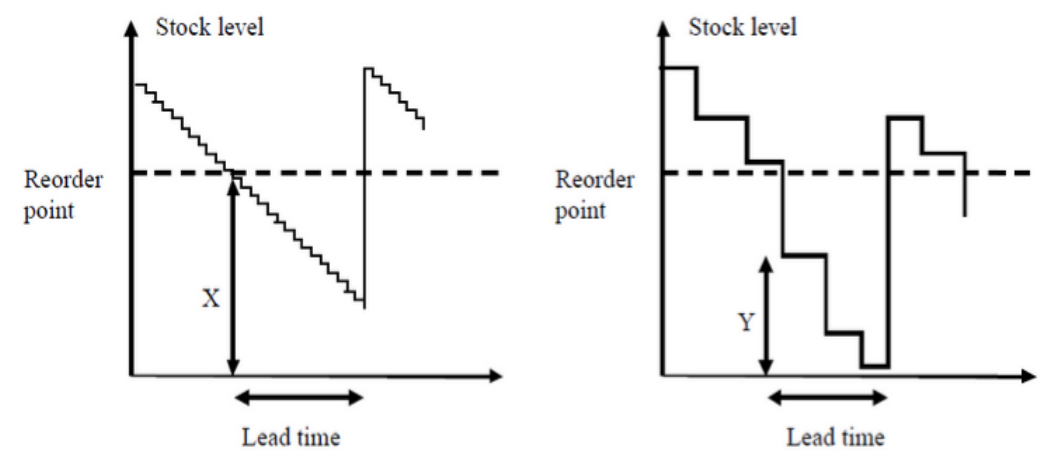

Fig 2. Re-order point behavior example.

Hadley \& Whitin (1963) formalized the q, R model in a costs framework, where the total amount of costs is composed by ordering, maintaining and backordering costs. Federgruen \& Zheng presented a simple and efficient algorithm to calculate a q, R optimal lineal policy in Q*; Zheng (1992) contributed with important ideas for the heuristic showing the utilization of EOQ formula instead of the optimal order quantity, $\mathrm{Q}^{*}$, finding the optimal order point, $r$, causes a cost increase for the order in a rate of no more than $1 / 8$. Also demonstrated when the saving in inventory is reflected, the relative total cost increase is much lower than in the worst scenario.

Priyan y Uthayakumar (2015) presented that even that the continuous review inventory model has been studied for several years, helping to minimize the related costs to the ordering quantities, lost sales and process order costs, exists some paradigms into the inventory areas. The most common is the assumption that received quantities are equal to the ordered quantities; which is a non-complete true asseveration due to the huge amount of variables during the process, packing and delivery moments. For all this reasons they developed a mathematical model including the stock out costs, these are located in the studied company we are studying.

\section{Problem Description}

The selected company is dedicated to manufacture mechanical seals in Tlaxcala. It has been running for more than 30 years and nowadays has 400 employees working in a 3 shifts scheme. Reviewing the general acquisition of components process we can highlight the suppliers' ship daily via FedEx / DHL due to the characteristics of size and weight of the part numbers. $70 \%$ of the suppliers are located in U.S. $20 \%$ are in Europe and $10 \%$ between Asia and Middle East. Actually the use the financial strategy of non-pure Just in Time (JIT), because of the always changing characteristics of the business, they have incorporated other strategies like the Vendor Management Inventory (VMI). 
The productive strategy is Make-to-Order, as they start producing until a sales order is entered and reflected into the ERP system. There are some parallel running processes with sales where drawings are developed, material specifications and creation of new codes when applies. This will help the final customer receive their material in the compromised lead time.

The company use an old fashioned ERP to follow up the open orders having an operational control, creating a data base visible for the other sites around the world. This tool was developed by IBM and have his boom during 90's. Nowadays it is still working in a proper way for the business requirements. The last massive parameterization was performed 5 years ago. However the buyers review individually their own part numbers before placing a new order. The business have a consecutive growth for the last 5 years, but we identified 770 part numbers (30\% approx.) with a decreasing usage because the engineering reviews do not need those pieces anymore. New business have been incorporated and calls for components with specific restrictions as FDA's compliance. As consequence new part numbers have been added to the warehouse stock ignoring the $\mathrm{ABC}$ classification; the last time they reviewed their safety stock levels was done in 2012. These are the mainly reasons why we cannot define if they have a overstock level, there are many logistical costs over the sky and an important lack of raw material acquisition planning, giving as a result penalties for stock outs and re-works for the rest of the involved areas with negative impact on the financial metrics.

The actual needs of the market demands less lead time or deliveries and improvement for the competitive prices with no quality issues. Other companies that produce the same type of seals are increasing the competences in the critical involved areas (Purchasing, Warehouse and Finances) where the major part of the expenses are reflected.

As a first stage an ABC classification was performed for the 144 suppliers with active orders during 2015, according to the part numbers volume supplied to the company. The result is that only one vendor has assigned the $33 \%$ of all the existing part numbers in loaded in the system. With the selected supplier, we worked in the second stage where an $\mathrm{ABC}$ classification was done for 2,636 items; using a coefficient of variation and pattern demand to establish the most accurate model to be used. If the coefficient of variation is less than $20 \%$ a deterministic model EOQ will be used, that determine the lot sizes for the economic order. Otherwise, if the value is higher than $20 \%$, the best option will be working with a q, R stochastic model, that will define the size of the order and re-order point with irregular pattern demand.

Due to the uncertainty in the demand, as the company works under personalized projects, a safety stock is needed only over the critical part numbers that can be used in multiple seals as a common base with long lead time enough to impact the customer order. During the third and last stage, the Safety stock was analyzed against the information loaded in the system with the intention of update the purchasing parameters. The implementation team was conformed of 3 departments Warehouse, Purchasing and Finances. 


\section{$4 \quad$ Methodology and Results}

\subsection{ABC Classification for Supplier and Components}

There are 24,059 items loaded into the system; only 7,879 items had movement during the last year. In order to narrow the scope a Pareto diagram was made where the assigned part numbers per vendor are shown, in Figure $3 \mathrm{~A}, \mathrm{~B}, \mathrm{C}, \ldots$ etc. represents the supplier name. In total we have 144 active suppliers delivering items, but only 20 of them have assigned the $80 \%$ of the total amount of part numbers.

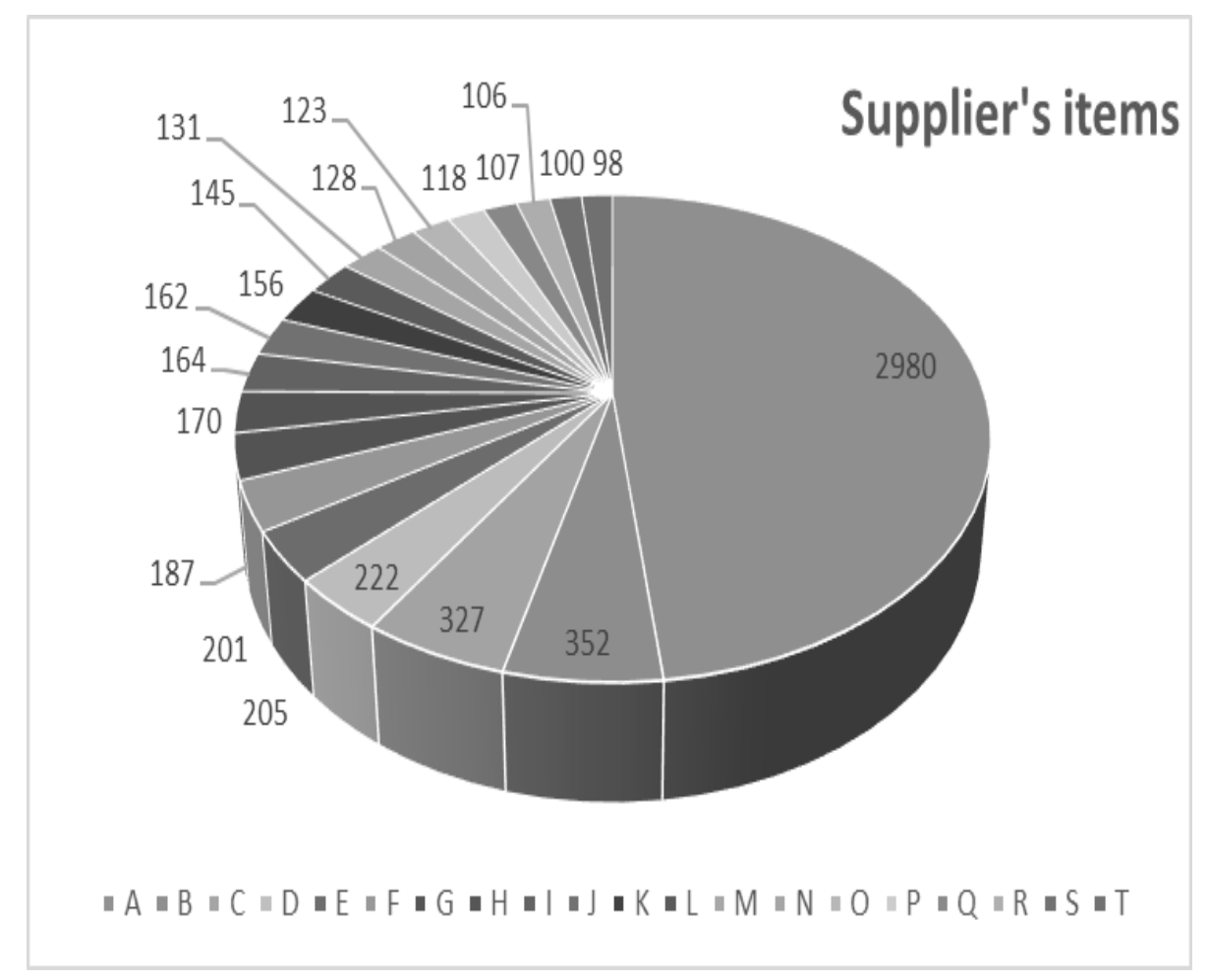

Fig 3. Items assigned per supplier.

The "A" supplier has 2,980 assigned items, because of that we will continue only with this supplier. A modification in that quantity of items will not only have effects of inventory reduction, a drastic logistical costs reduction as the inventory models explains.

Taking 2,980 items, we proceed with ABC classification as shown in the following charts; Profit based on (Chart 1a) and Usage based on (Chart 1b) with 2015 database to have an assertive result.

In the second stage we considered that the first simple of 91 items is not enough to specify a method, not even the model to use with the other part numbers. We took the decision to open the sample to $100 \%$, so all the part numbers assigned to the supplier will be reviewed. 


\begin{tabular}{|c|c|c|}
\hline \multicolumn{3}{|c|}{ PROFIT BASED CLASSIFICATION } \\
\hline A & B & C \\
\hline 701561-Q1 & K23M1875GX3 & 568138AF \\
\hline 393985PS3 & 568141WG56 & 4N02100CK \\
\hline MLB32752919 & MLA37358225 & MEAX8840252 \\
\hline C0164845YO & KU3R1125333 & 4R0429NL \\
\hline TCN3029 & $4 \mathrm{~N} 01736 \mathrm{NL}$ & 621533DB \\
\hline $3 R 26481 Y O$ & 4R13467DB & $568112 \mathrm{AF}$ \\
\hline $523499011-Q 1$ & KCUM2250R33 & Y53A5500AC3 \\
\hline KU3R1750333 & $568333 Z \mathrm{~V}$ & Y5FQ3375M33 \\
\hline TCN2624 & KR8G2750G33 & MYCG5875AJ3 \\
\hline 3R98758K30 & KR3D2625FA3 & 670719DB \\
\hline TCN2764 & TIRM2000X33 & 614608GE \\
\hline B0235952-Q1 & MLB33460633 & MKAX88402BE \\
\hline B0246289-Q1 & 668815 LV & MCA23280714 \\
\hline MLB32752906 & MEAX8840239 & 4N02099CK \\
\hline 4922609 1 2-Q1 & 4N01730AI & MIAX8840250 \\
\hline $483650412-Q 1$ & 3N49141DB & 618947MG \\
\hline AU3J1875MZ3 & KIRM2250TK3 & 626671LP \\
\hline MLB32752920 & TCRM1500X33 & 568357AF \\
\hline KU3C1875C33 & $568234 \mathrm{GU}$ & 4N11498GE \\
\hline 4R0440X902 & 4R2893NL & K43R1000333 \\
\hline Total & Total & Total \\
\hline 526 & 747 & 1683 \\
\hline
\end{tabular}

Chart 1a. Profit.

\begin{tabular}{|c|c|c|}
\hline \multicolumn{3}{|c|}{ USAGE BASED CLASSIFICATION } \\
\hline A & B & C \\
\hline MLA37358228 & 4R39511DB & MNA20442233 \\
\hline C0012107NL & $4 \mathrm{R} 3483 \mathrm{Cl}$ & UR437CK \\
\hline C0012112X974 & 4N02083X409 & $568150 M G$ \\
\hline C0195336ZZ & MYCG5115AB3 & MYCD1375CA3 \\
\hline MLA21480433 & 4R15512DB & 568222MG \\
\hline MKAX8840217 & C0013644NL & $4 \mathrm{R} 2888 \mathrm{Cl}$ \\
\hline MKAX8840212 & 4R2951Cl & K23D3000Q33 \\
\hline MLA37358225 & $4 \mathrm{R} 3269 \mathrm{Cl}$ & 156407GE \\
\hline 668855DB & $568031 \mathrm{MG}$ & 664282DB \\
\hline C0195337ZZ & 4R45404DB & 4R0437HU \\
\hline 668802DB & 4R3148Z7 & US $325 \mathrm{CK}$ \\
\hline MKAX8840254 & MIAX8840250 & 4N01767DB \\
\hline C0012111X974 & MKAX8840227 & 07001423300 \\
\hline MKAX8840209 & 4R0457DY & $4 \mathrm{~N} 01731 \mathrm{Cl}$ \\
\hline MKAX8840215 & $668853 \mathrm{DB}$ & 4SIPG711X \\
\hline C0201666ZZ & 670453DB & 616267GU \\
\hline $4 \mathrm{R} 0434 \mathrm{Cl}$ & C0013641CK & UR212CK \\
\hline 670425DB & MKAX88402CA & 568339MG \\
\hline C0012118X974 & C0013647X974 & 568226MG \\
\hline UR243CK & 4R3150ZZ & 4SIPG714 \\
\hline Total & Total & Total \\
\hline 91 & 464 & 2425 \\
\hline
\end{tabular}

Chart 1b. Usage.

\subsection{Coefficient of Variability}

This operation is needed to determine if the used model will be deterministic or probabilistic; in order to take the best decision, the following steps are recommended:

1) Calculate estimated average demand $\mathrm{d}$ for each period:

$$
\bar{d}=\frac{1}{n} \sum_{1=l}^{i=n} d i
$$

2) Calculate estimated variance $D$ for each period:

$$
\text { Est.var } D=\frac{1}{n} \sum_{1=l}^{i=n} d i^{2}-\overline{d^{2}} \text {. }
$$

3) Calculate estimated relative demand variation (also called as coefficient of variation). The final amount is represented as $\mathrm{CV}$ :

$$
V C=\frac{\text { est. } \operatorname{var} D}{\bar{d}^{2}} .
$$

If the coefficient is lower than $0.20(20 \%)$ a deterministic model can be used; otherwise, the demand is too instable and a probabilistic model must be used. After calculate the coefficient of variation for all the classified A, B, C items we can observe the behavior in Chart 2a showed below: 
A

\begin{tabular}{|ccl|}
\multicolumn{1}{|c}{$\%$} & No. Items & Pattern \\
\hline 0.90 & 81.00 & Regular \\
0.10 & 10.00 & Irregular \\
\cline { 2 - 2 } & 91.00 & \\
\hline
\end{tabular}

$\%$ No. Items Model

$0.64 \quad 58.00 \quad$ Deterministic

$0.37 \quad 33.00 \quad$ Probabilistic

91.00
B

\begin{tabular}{|c|c|c|}
\hline$\%$ & No. Items & Pattern \\
\hline 0.34 & 157.00 & Regular \\
\hline \multirow[t]{2}{*}{0.66} & 307.00 & Irregular \\
\hline & 464.00 & \\
\hline$\%$ & No. Items & Model \\
\hline 0.08 & 35.00 & Deterministic \\
\hline \multirow[t]{2}{*}{0.92} & 429.00 & Probabilistic \\
\hline & 464.00 & \\
\hline
\end{tabular}

C

\begin{tabular}{|c|c|c|}
\hline$\%$ & No. Items & Pattern \\
\hline 0.02 & 38.00 & Regular \\
\hline \multirow[t]{2}{*}{0.98} & $2,387.00$ & Irregular \\
\hline & $2,425.00$ & \\
\hline$\%$ & No. Items & Model \\
\hline 0.003 & 7.00 & Deterministic \\
\hline \multirow[t]{2}{*}{0.997} & $2,418.00$ & Probabilistic \\
\hline & $2,425.00$ & \\
\hline
\end{tabular}

Chart 2a. Behavior for ABC classification according to Coefficient of variation.

We can appreciate the part numbers classified as "A", most of them have a regular pattern and a deterministic method can be applied due to their coefficient of variation. Not in the same way for the rest of the items; the scene changes for the B and C classified items; where we can see most of the items have an irregular pattern and it is no possible to apply the same method that is why we call for a stochastic one.

\begin{tabular}{lrcc}
\multicolumn{4}{c}{ ABC } \\
\multicolumn{1}{c}{ Pattern } & No. Items & $\%$ & \\
Regular & 276.00 & $9 \%$ & \\
Irregular & $2,704.00$ & $91 \%$ & \\
\cline { 2 - 3 } Total & $2,980.00$ & & \\
$\quad$ Model & No. Items & $\%$ & \\
Deterministic & 100.00 & $3 \%$ & EOQ \\
Probabilistico & $2,880.00$ & $97 \%$ & QR \\
\cline { 2 - 3 } Total & $2,980.00$ & &
\end{tabular}

Chart 2b. Global behavior and method to be used according to Coefficient of variation.

Into the Chart $2 b$ shows that the EOQ will be used for the $3 \%$ of the items with the coefficient of variation acceptable for a deterministic method. For the rest of the items $\mathrm{B} \& \mathrm{C}$ mostly we decided to use the continuous review q, R model.

\subsection{Economic Order Quantity (EOQ)}

In this stage of the Project we realized the economic lot estimated using the general equation for EOQ model (4) as is showed below:

where:

$$
\mathrm{Q} *=\sqrt{\frac{2 D S}{H}},
$$

$\mathrm{D}=$ Yearly unitary demand.

$\mathrm{S}=$ Ordering cost for each requirement.

$\mathrm{H}=$ Holding monetary cost.

The total logistical cost (5) is obtained summarizing the order cost plus the acquisition cost plus the holding inventory cost: 


$$
\mu(q)=\frac{k d}{q}+c d+\frac{h q}{2} .
$$

The frequency (6) for setting a new order is:

$$
T^{*}=\frac{q^{*}}{d}
$$

The order number (7) is given by the consume (demand) between the optimal quantity to be ordered:

$$
n=\left(d / q^{*}\right) .
$$

As a result we have a total logistical cost of $\$ 4^{\prime} 269,694$ pesos; due to the order cost is low, the optimal quantity to order is high; and this is reflected in holding inventory for long periods of time. Also we obtained an average of 4.2 orders per year for almost all the part numbers. Inside the Chart 3 we can see the relation between the part numbers according to their classification and the percentile of the logistical cost that represents for the 100 reviewed pieces.

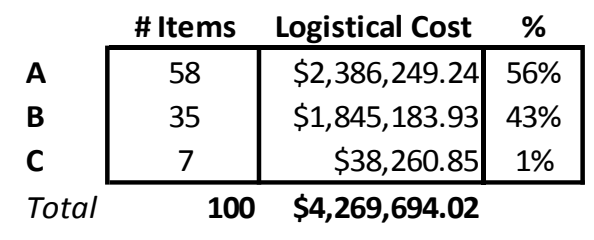

Chart 3. Total logistical cost for EOQ model.

\subsection{Continuous Review Model with Uncertain Demand $(q, R)$}

For this project we used the $\mathrm{q}, \mathrm{R}$ inventory model with a random demand. After setting the needed equations we will have an optimal value for the limits approach, without leaving the order limits allowed for the inventory value, where the theorems will prove the supposed changes in the following orders. It is taken this analysis because we proposed a periodic review with emergency safety replenishment. Characterized with short order periods, absorbing the order cost. Below we can see the equations for the results obtainment.

The standard deviation (8) is calculated during the lead time, multiplying the demand's standard deviation with square root of lead time:

$$
S_{d}^{\prime}=S_{d} \sqrt{L}
$$

The re-order point (9) is the result of multiplying the mensual demand with the lead time expressed in months plus the adjusted standard deviation with the $\mathrm{Z}$ value to the normal distribution with a customer's service level previously defined:

$$
R=d * L+z_{C S L} * S_{d}^{\prime} .
$$

The order size (10) tells us we should calculate the square root of two times the order cost multiplied with the monthly demand between the holding inventory costs: 


$$
q=\sqrt{\frac{2 k d}{h}}
$$

The ratio of the standard deviation (11) stays out or do not complies with the demand 1-s'd*Ez/q gives us the number of non-supplied pieces.

The stock outs ratio given a $\mathrm{Z}$.

Fs $(\mathrm{z})=$ Accumulated normal standard distribution function.

Fs $(\mathrm{z})=$ Density of normal standard distribution function. This is the point where occurs the probability:

$$
E_{z}=z *\left[F_{s}(z)-1\right]+f_{s}(z) .
$$

The total logistical cost (12) $\left[\mu\left(q^{*}\right)\right]$ is given by the following equation:

$$
\mu(q)=\frac{k d}{q}+h\left[\frac{q}{2}+z_{C S L} * S_{d}^{\prime}\right] c d+\frac{d}{q}\left(u * s_{d}^{\prime} * E_{2}\right) .
$$

FR (13) is defined per the following equation:

$$
F R=1-\frac{\left(\frac{d}{q}\right) * S_{d}^{\prime} * E_{z}}{d}=1-\frac{S_{d}^{\prime} * E_{z}}{d} .
$$

As a result we obtained a total logistical cost of $\$ 5^{\prime} 861,794$ pesos. The $\mathrm{q}, \mathrm{R}$ model considers a cyclical service level of $100 \%$ and suggests a re-order point with a lot size for each part number. See the Chart 4 to review the relation between the articles with the logistical costs and the ratio that represents each category.

\begin{tabular}{l|c|r|c|} 
& \multicolumn{1}{c}{ \# Items } & \multicolumn{1}{c}{ Logistical Cost } & $\%$ \\
\cline { 2 - 4 } A & 33 & $\$ 34,152.06$ & $1 \%$ \\
B & 429 & $\$ 539,495.40$ & $9 \%$ \\
C & 2418 & $\$ 5,288,147.06$ & $90 \%$ \\
\cline { 2 - 4 } Total & $\mathbf{2 8 8 0}$ & $\$ 5,861,794.52$ &
\end{tabular}

Chart 4. Total logistical cost for $\mathrm{q}, \mathrm{R}$ model.

\subsection{Safety Stock (SS)}

The safety stock inventory is an additional quantity for an item inside your warehouse with the objective of reduce the production stock outs. There are additional associated costs that must be considered during the calculation; however the holding inventory cost can be lower than the cost for losing a client if the delivery is not completed timely and properly.

We took 920 items with a safety stock inventory loaded with the selected supplier. The 2,060 pending items do not have a safety stock loaded and will be excluded from our analysis. We decided to perform an analysis between the loaded inventories into the system against a proposal of re-ordering points with the $\mathrm{q}, \mathrm{R}$ model. After the estimations, we analyzed the implementation team to verify the obtained results. 


\section{$5 \quad$ Discussion of Results}

At the beginning of this project I have no idea where to find a problematic situation inside the organization. I started downloading different reports in order to see if I can get some clues about a malfunction of any area. Suddenly I get trapped in a huge quantity of information that have no sense for me. I have to accept that into the theory the problems looks like if all could be located easily. After several meetings with different areas, the situation of the inventory came out and the opportunity to work in that issue was set.

The part numbers trend through the analyzed period of time gave us a general overview of the behavior of the sales, and the inventory level effects. The Figure 4a, $4 \mathrm{~b}, 4 \mathrm{c} \& 4 \mathrm{~d}$ shows some examples of one analyzed item and the movement during the last 5 years. The graphics are based in the yearly usage showing the pieces during the period of time mentioned before.

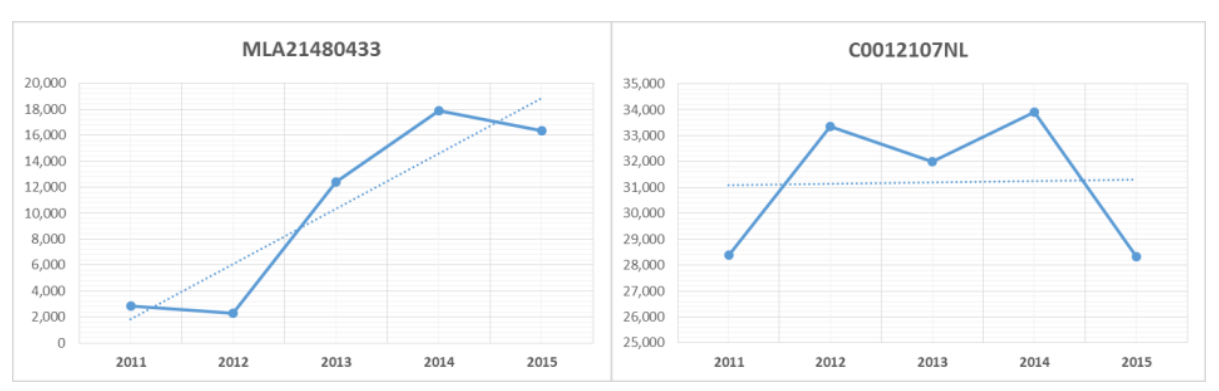

Fig 4a.

Fig 4b.

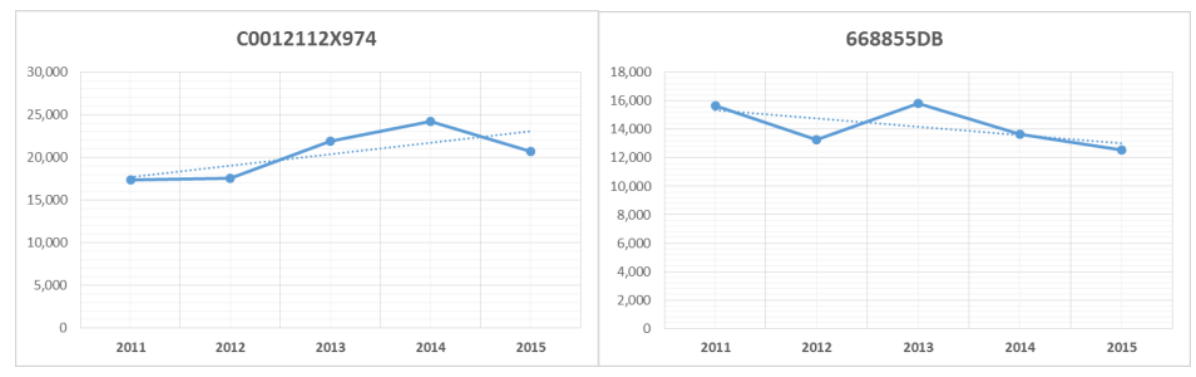

Fig 4c.

Fig 4d.

\begin{tabular}{|l|c|c|c|c|}
\hline Concept & Actual & Model & Difference & $\%$ \\
\hline Items with SS & 920 & 919 & -1 & $0.1 \%$ \\
\hline Inventory value & $\$ 1,046,076.00$ & $\$ 996,888.23$ & $-\$ 49,187.77$ & $5 \%$ \\
\hline
\end{tabular}

Chart 5. Actual status against proposed model values.

As we can see into the graphics the behavior of the part numbers are as many as the customers' requests. It is a challenging situation due to the nature of the business, and a great opportunity to solve this issues with the tools available in the science theory. 
Nowadays the inventory levels into the companies represents one big opportunity for creating savings without the need additional investments for the operational processes. Every day the highest levels of the organizations increases their awareness about the negative effect of having money stocked into the shelves. In order to accomplish the purpose of this project a selection of logistical tools were used with mathematical operations the values represents the path they are following up.

The inventory value at the beginning of the project was $\$ 1^{\prime} 046,076$ pesos with 920 part numbers with a safety stock inventory loaded, representing $8 \%$ of the total value of the analyzed plant inventory. The modification in the minimal lots suggest $58 \%$ reduction of the inventory value and decrease of 691 part numbers in the safety stock items loaded. After changes were applied the saving impact is immediately, even when the available inventory in plant was not considered. This variable was discarded for practical reasons for this project, because we do not have control over the demand and due to the restricted access to the sales department information. Finally the inventory will reach the objective level of $\$ 435,854$ pesos. Please refer to the Chart 5 to see the initial amount of loaded items with safety stock and their value in pesos, also we can see the difference that represents the change in parameters, where a $5 \%$ reduction is showed.

The idea of reduce the inventory level without any investment had a great acceptance, and that is why we reviewed each one of the 920 items, leaving out the obsolete, discontinued or substituted items; also all those special items that only were bought one time without requirement. After the complete review, the implementation team concluded with the Chart 6 values, for reaching an inventory level decreased $58 \%$.

\begin{tabular}{|l|c|c|c|c|}
\hline Concept & Actual & Model & Difference & $\%$ \\
\hline Items with SS & 920 & 691 & -229 & $24.9 \%$ \\
\hline Inventory value & $\$ 1,046,076.00$ & $\$ 435,845.67$ & $-\$ 610,230.33$ & $58 \%$ \\
\hline
\end{tabular}

Chart 6. Actual state against final agreement.

Chart 7a \& 7b shows the inventory value proposed for both cases: $\mathrm{q}, \mathrm{R}$ model and final agreement with $\mathrm{ABC}$ classification. We can see the dramatically decrease in items with $\mathrm{C}$ classification and the value increase for A classified items.

\begin{tabular}{|c|c|c|c|c|c|c|c|}
\hline \multicolumn{4}{|c|}{ q, R Model } & \multicolumn{4}{|c|}{ Final Agreement } \\
\hline Clasif & Items & Value \$ & $\%$ & Clasif & Items & Value \$ & $\%$ \\
\hline A & 83 & $\$ 63,728.77$ & $6 \%$ & A & 82 & $\$ 70,125.72$ & $16 \%$ \\
\hline B & 345 & $\$ 347,503.09$ & $35 \%$ & B & 327 & $\$ 152,672.11$ & $35 \%$ \\
\hline C & 491 & 585.656 .37 & $59 \%$ & C & 282 & $\$ 213,047.84$ & $49 \%$ \\
\hline Total & 919 & $\$ 411,231.86$ & & Total & 691 & $\$ 435,845.67$ & \\
\hline
\end{tabular}

Chart 7a.

Chart 7b. 


\section{References}

1. Aznar, M.: Organización de Almacenes y Control de Inventarios, México: ECASA.P1 (1986)

2. Dhoka, D., Choudary, L.: ABC Classification for Inventory Optimiztion, IOSR Journal of Business and Management (IOSR-JBM), e-ISSN: 2278-487X, p-ISSN: 2319-7668, vol. 15, (Nov. - Dec. 2013), pp. 38-41 (2013)

3. Heizer, J., Render. B.: Administración de Operaciones, México: PEARSON Educación, pp. 978-987 (2009)

4. Hopp, W. J., Spearman, M. L., Zhang, R. Q.: Easily Implementable Inventory Control Policies. Operations Research, pp. 327-340 (1997)

5. Mattson, S.A.: Inventory control in environments with short lead times. International Journal of Physical Distribution \& Logistics Management, vol.37, pp. 115-130 (2007)

6. Nahmias, S.: Análisis de la producción y las operaciones, México: McGraw Hill (2007)

7. Pratap, M., Singh, H.: Evaluation and Economic Selection of Raw Materials Inventory Control Policies: A Case Study. Journal of Operations Management, 7(4), pp. 21-30 (2008)

8. Priyan, S., Uthayakumar, R.: Continuous review inventory model with controllable lead time, lost sales rate and order processing cost when the received quantity is uncertain. Journal of Manufacturing Systems, pp. 23-33 (2015)

9. Quing, L., He, X., Shaohui, Z.: Periodic-review inventory systems with random yield and demand: Bounds and heuristics. IIE Transactions, no. 40, pp. 434-444 (2008)

10. Roach, B.: Origin of the Economic Order Quantity Formula; Transcription or Transformation? Management Decision, vol. 43, pp. 1262-1268 (2005)

11. Sipper, D., Bulfin, R. L.: Planeación y Control de la Producción, México: McGraw Hill (1998) 